\title{
Targeting of distinct signaling cascades and cancer-associated fibroblasts define the efficacy of Sorafenib against prostate cancer cells
}

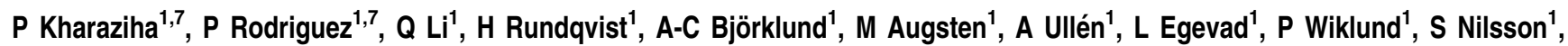 \\ G Kroemer $^{2,3,4,5,6}$, D Grander ${ }^{1,7}$ and T Panaretakis ${ }^{\star, 1,7}$
}

Sorafenib, a multi-tyrosine kinase inhibitor, kills more effectively the non-metastatic prostate cancer cell line 22Rv1 than the highly metastatic prostate cancer cell line PC3. In 22Rv1 cells, constitutively active STAT3 and ERK are targeted by sorafenib, contrasting with PC3 cells, in which these kinases are not active. Notably, overexpression of a constitutively active MEK construct in 22Rv1 cells stimulates the sustained phosphorylation of Bad and protects from sorafenib-induced cell death. In PC3 cells, Src and AKT are constitutively activated and targeted by sorafenib, leading to an increase in Bim protein levels. Overexpression of constitutively active AKT or knockdown of Bim protects PC3 cells from sorafenib-induced killing. In both PC3 and 22Rv1 cells, Mcl-1 depletion is required for the induction of cell death by sorafenib as transient overexpression of Mcl-1 is protective. Interestingly, co-culturing of primary cancer-associated fibroblasts (CAFs) with 22Rv1 or PC3 cells protected the cancer cells from sorafenib-induced cell death, and this protection was largely overcome by co-administration of the Bcl-2 antagonist, ABT737. In summary, the differential tyrosine kinase profile of prostate cancer cells defines the cytotoxic efficacy of sorafenib and this profile is modulated by CAFs to promote resistance. The combination of sorafenib with Bcl-2 antagonists, such as ABT737, may constitute a promising therapeutic strategy against prostate cancer.

Cell Death and Disease (2012) 3, e262; doi:10.1038/cddis.2012.1; published online 26 January 2012

Subject Category: Cancer

Prostate cancer is the most frequent malignancy in men worldwide. Localized prostate cancer is efficiently treated by androgen deprivation therapy, radiotherapy or surgery. Since 2004, when the data from TAX 327 and SWOG 9916 trials showed survival benefits following docetaxel, this compound has been standard treatment for patients with metastatic castration-resistant prostate cancer (CRPC). ${ }^{1}$ Unfortunately, docetaxel treatment has improved survival only modestly with an average median survival increase compared with mitoxantrone of $\sim 3$ months. Multiple tyrosine kinase inhibitors (TKI) with anti-angiogenic targeting profiles such as sorafenib and sunitinib have been evaluated in metastatic CRPC, but data are yet limited.

Since 1996, when the first attempt was made to profile the expression of tyrosine kinases in prostate cancer cells, significant progress has been made in mapping the signaling pathways important for the development of prostate cancer and in particular CRPC. ${ }^{2}$ The activation of both receptor tyrosine kinases (RTK), such as platelet-derived growth factor receptor (PDGFR), vascular endothelial growth factor (VEGFR) and epidermal growth factor receptor (EGFR), and that of nonreceptor tyrosine kinases (NRTK), such as Src and LCK, has been well described. ${ }^{3,4}$ Owing to the critical role of RTK and NRTK in prostate cancer, they constitute prospective therapeutic targets for an improved clinical management of CRPC.

The signaling cascades downstream of RTKs and NRTKs include mainly the Ras/Raf/MEK/ERK, JAK/STAT and the PI3K/AKT pathways. In particular, the Ras/Raf/MEK/ERK signaling cascade has a pivotal role in the molecular circuitry of CRPC, and the majority of the RTKs upregulated in prostate cancer have been shown to activate Ras. ${ }^{5}$ Several studies have shown that the Ras/Raf/MEK/ERK activity positively correlates with disease progression. ${ }^{6}$ As there are very few reports on activating mutations in the Ras/Raf/MEK/ERK pathways, it is likely that the autocrine or paracrine activation of their upstream activators, RTK and NRTK, accounts for the

\footnotetext{
${ }^{1}$ Department of Oncology-Pathology, Cancer Centrum Karolinska, Karolinska Institutet, Stockholm, Sweden; ${ }^{2}$ INSERM, U848, 39 rue Calmette Desmoulins, Villejuif, France; ${ }^{3}$ Metabolomics Platform, Institut Gustave Roussy, Pavillon de Recherche 1, Villejuif, France; ${ }^{4}$ Centre de Recherche des Cordeliers, Paris, France; ${ }^{5}$ Pôle de Biologie, Hôpital Européen Georges Pompidou, Paris, France and ${ }^{6}$ Paris Sorbonne Cité, Université Paris Descartes, Faculté de Médecine, Paris, France ${ }^{*}$ Corresponding author: T Panaretakis, Department of Oncology/Pathology, Cancer Centrum Karolinska, R8:03, Karolinska Institutet and University Hospital, S-17176 Stockholm, Sweden. Tel: + 468517732 18; Fax: + 4683390 31; E-mail: theoharis.panaretakis@ki.se

${ }^{7}$ These authors contributed equally to this work.

Keywords: prostate cancer; tyrosine kinase inhibitor; sorafenib; apoptosis; autophagy; ABT737

Abbreviations: CRPC, castration-resistant prostate cancer; RTK, receptor tyrosine kinase; PDGFR, platelet-derived growth factor receptor; VEGFR, vascular endothelial growth factor; EGFR, epidermal growth factor receptor; NRTK, non-receptor tyrosine kinases; ERK, extracellular-signal-regulated kinase; JAK, janus kinase; STAT, signal transducer and activator of transcription; PI3K, phosphoinositide 3-kinase, MCL-1, myeloid cell leukemia-1; PTEN, phosphatase and tensin homolog; FLT3, fms-like tyrosine kinase receptor-3; TKI, tyrosine kinase inhibitors; Sor, Sorafenib, CAF, cancer-associated fibroblast; $\alpha$-SMA, alpha smooth muscle actin; EGF, epidermal growth factor; BPE, bovine pituitary extract; 3-MA, 3-methyladenine; SDS-PAGE, sodium dodecyl sulfate polyacrylamide gel electrophoresis; $\mathrm{CQ}$, chloroquine; TMRE, tetramethylrhodamine, ethyl ester

Received 03.8.11; revised 07.12.11; accepted 30.12.11; Edited by P Salomoni
} 
induction of this pathway. Furthermore, ERK not only promotes growth but also protects from cell death by the induction and stabilization of anti-apoptotic proteins (e.g., Bcl-2, Bcl-xL and Mcl-1) or the inhibition of pro-apoptotic mediators (e.g., the phosphorylation of Bad). ${ }^{7}$

The other main downstream target of RTKs and NRTKs, the PI3K/AKT pathway has also been increasingly implicated in the development and progression of prostate cancer. Several mechanisms have been proposed for the aberrant activation of the PI3K/AKT pathway, namely activating mutations in the catalytic subunit of PI3 K and AKT, loss of expression of PTEN and autocrine/paracrine signaling from the RTKs and NRTKs. $^{8,9}$ In fact, PTEN homozygous deletions have been detected in $20-30 \%$ of metastatic prostate cancer and more than $50 \%$ of prostate carcinomas exhibited increased AKT1 kinase activity. ${ }^{10,11}$ Thus, AKT has been shown to have a key role in protecting cells from various types of apoptotic stimuli by phosphorylating and inhibiting downstream targets such as the Forkhead family transcription factors, which are known to regulate, among other proteins, the expression of the BH3-only protein Bim. ${ }^{12}$

The discovery that certain RTKs and NRTKs may be activated in prostate cancer has opened the way for the therapeutic usage of TKIs. One clinically established (e.g., hepatocellular carcinoma, renal cell carcinoma) TKI is sorafenib that mainly targets Raf1, PDGFR $\beta$, VEGFR, FLT3 and $\mathrm{c}-\mathrm{Kit}^{13}{ }^{13}$ Sorafenib appears to be a good candidate for the treatment of prostate cancer, because several of the pathways targeted by this TKI are activated, especially in CRPC. Thus, sorafenib induces cell death and autophagy in prostate cancer cell lines, and sorafenib reduces the growth of human prostate cancers that have been xenografted on immunodeficient mice (Ullen et al. ${ }^{14}$ and personal communication to Anders Ullén). During the last years, three independent and rather small phase II trials have evaluated the effect of sorafenib in CRPC. ${ }^{15-17}$

The crosstalk between the tumor microenvironment and prostate cancer cells is considered to be critical for the progression of cancer. ${ }^{18}$ This is primarily due to the secretion of cytokines, which in a paracrine fashion (i) activate RTKs and NRTKs that promote the survival and proliferation of prostate cancer cells in the development of CRPC and (ii) activate fibroblasts, recruit inflammatory cells and remodel the extracellular matrix. ${ }^{19}$ Moreover, the tumor stroma can 'protect' cancer cells from the cytotoxic insults exerted by anticancer agent, thus conferring therapeutic resistance. On theoretical grounds, inhibitors that target tyrosine kinase signaling in both cancer cells and the tumor microenvironment might be particularly efficient.

In the present study we aimed at delineating the molecular mechanisms of sorafenib-induced cell death in two prostate cancer cell lines with distinct metastatic potential. The Raf/ MEK/ERK signaling cascades that leads to phosphorylation/ inactivation of Bad and upregulation of the anti-apoptotic $\mathrm{Bcl}-2$ family members is critical for the survival of $22 R v 1$ cells and sorafenib, by targeting this signaling cascade is highly efficacious in killing these cells. In contrast, PC3 cells rely on the Src/AKT pathway, which in turn leads to inhibition of Bim expression and targeting of this pathway by sorafenib sensitizes PC3 cells to apoptosis induction. Inhibition of cytoprotective autophagy ameliorates sorafenib-induced cell death. In addition, combination therapy with the Bcl-2 antagonist, $A B T 737$, is particularly effective against the highly metastatic PC3 cell line and also revert the protection mediated by cancer-associated fibroblasts (CAFs).

\section{Results}

Sorafenib induces caspase-dependent cell death in Prostate cancer cells. We previously described that sorafenib- (Sor) induced cell death in 22Rv1 and PC3 prostate cancer cells. ${ }^{14}$ Treatment of $22 \mathrm{Rv} 1$ and PC3 with sorafenib led to a time dependent increase in cell death, with 22Rv1 being more sensitive than PC3 cells (Figure 1a). Sorafenib induced minor changes in the cell cycle distribution with 22Rv1 exhibiting an S phase arrest and PC3 a G0/G1 arrest (Supplementary Figure 1). Treatment of 22Rv1 with sorafenib induced a modest decrease in mitochondrial membrane potential $\left(\Delta \Psi_{\mathrm{m}}\right)$, as determined with the $\Delta \Psi_{\mathrm{m}^{-}}$ sensitive dye TMRE, and a concomitant increase of cells that exposed Annexin V. In contrast, PC3 cells responding to sorafenib demonstrated an almost complete dissipation of their mitochondrial membrane potential, which was followed by an increase in the Annexin $\mathrm{V}^{+}$population (Figure 1a and b). However, despite the substantial decrease in $\Delta \Psi_{m}$, only a small fraction of cells released cytochrome $c$ from their mitochondria (Figure 1c).

With the aim to investigate the mechanism of cell death induced by sorafenib in 22Rv1 and PC3 cells, a number of classical apoptotic markers were examined (Figure 1d). 22Rv1 cells responding to sorafenib demonstrated cleaved Bax, activation of caspases, cleavage of PARP and processing of AIF, characteristic of its translocation to the cytoplasm (Figure 1d). In PC3, there was only a small increase in active caspase-7 and PARP cleavage after $48 \mathrm{~h}$ of treatment. Pretreatment of $22 \mathrm{Rv} 1$ and $\mathrm{PC} 3$ with the broad-spectrum caspase inhibitor Z-VAD-fmk, followed by sorafenib, partially inhibited cell death in both cell lines, suggesting that caspasedependent processes contribute to cell killing by sorafenib (Figure 1d). A chemical inhibitor of the pro-necrotic RIP1 kinase, necrostatin1, did not confer significant cytoprotection against sorafenib (Figure 1e). In summary, the data indicate that 22Rv1 manifest classical signs of apoptosis within $24 \mathrm{~h}$ of sorafenib treatment, whereas PC3 cells demonstrate a reduced and delayed kinetics of apoptosis.

Inhibition of ERK phosphorylation is necessary, but not sufficient for sorafenib-induced apoptosis in 22Rv1 cells. We determined whether and to which extent sorafenib might mediate its pro-apoptotic action by inhibiting the Raf/MEK/ERK pathway. ERK exhibited a constitutive activating phosphorylation in 22Rv1, and this phosphorylation was inhibited by sorafenib in a time dependent manner (Figure $2 a$ and $b$ ), whereas ERK was not activated in PC3 cells. Chemical inhibition of MEK1 with U0126 by itself induced cell death in 22Rv1 cells, and the combination of U0126 plus sorafenib did not kill more 22Rv1 cells than sorafenib alone (Figure 2c). U0126 did not have any effect in PC3 (Figure 2c). 
a

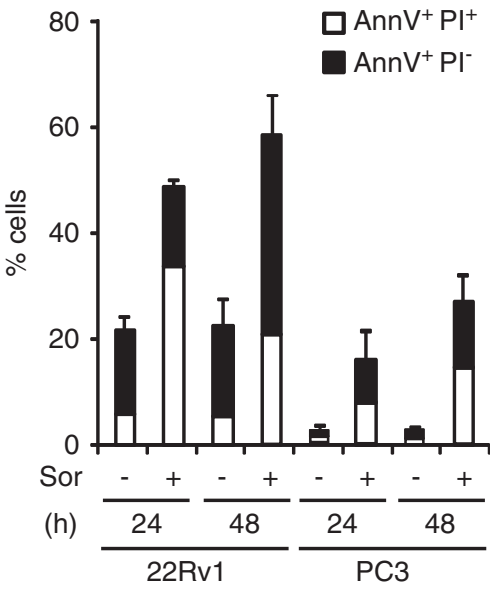

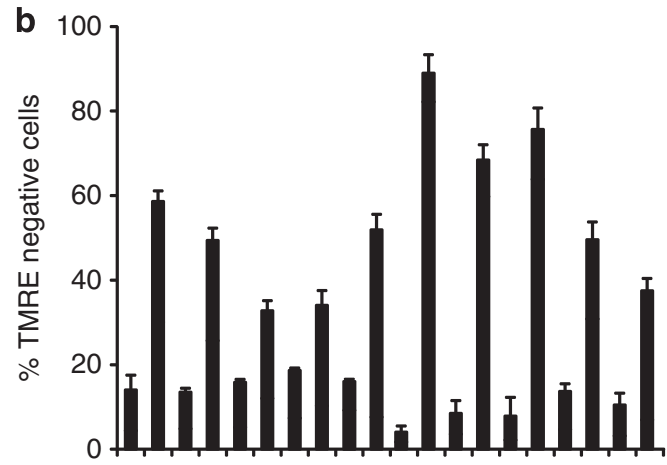

Sor $-+-+-+-+-+-+-+-+\cdot+-+$

(h) $\frac{\pi}{4} \frac{-1}{16} \frac{+}{24} \frac{+}{48} \frac{+}{8} \frac{+}{16} \frac{+}{24} \frac{+}{48}$ c

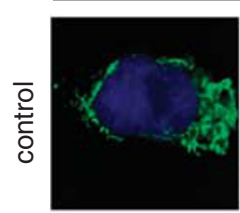

22Rv1
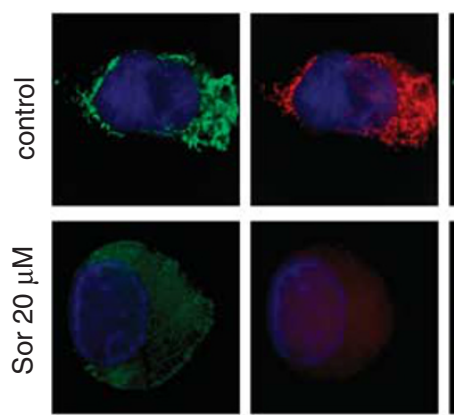
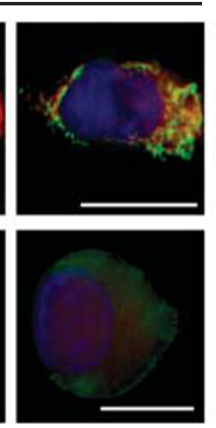

Mitotracker-Cytochrome c DAPI

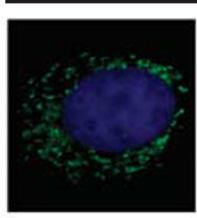

PC3
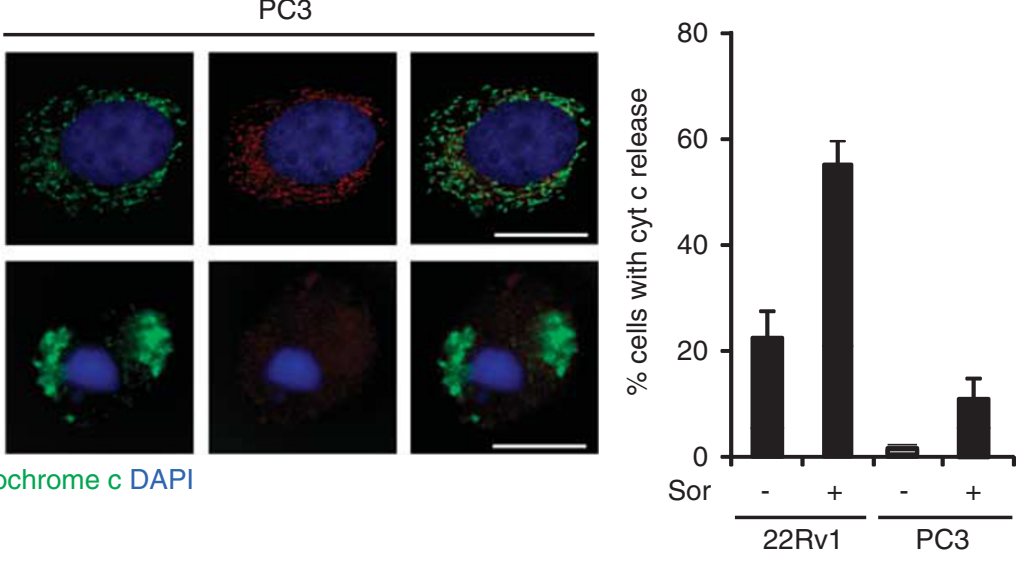

d

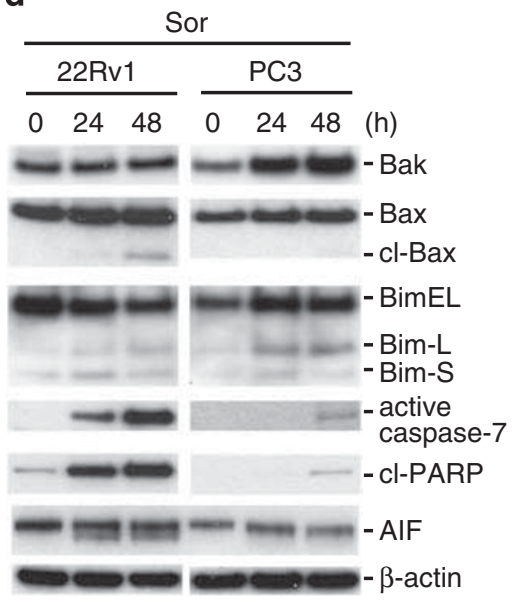

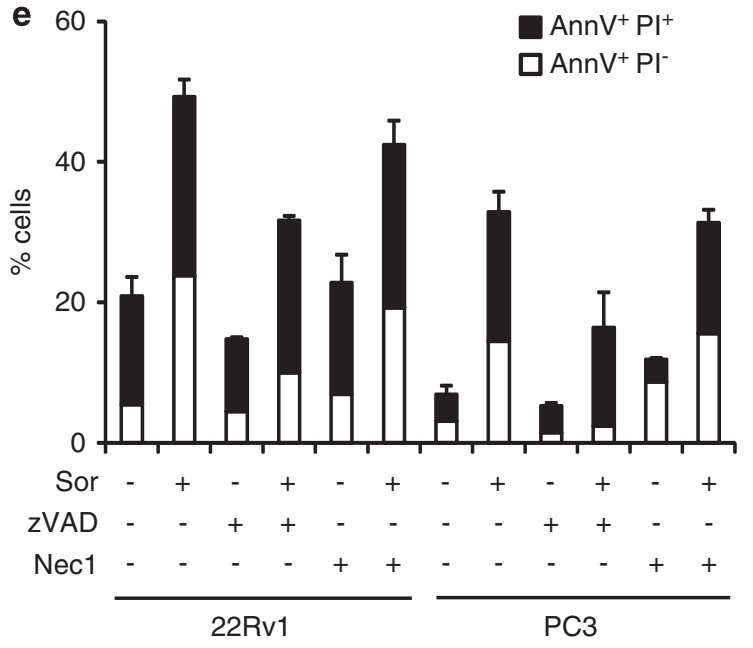

Figure 1 Sorafenib induces caspase-dependent and independent cell death in Prostate cancer cells. (a) Quantitative analysis of Annexin V/PI-positive, 22Rv1 and PC3 cells treated with $20 \mu \mathrm{M}$ sorafenib (Sor) for the indicated time points (means \pm S.D., $n \geq 3$ ); (b) Quantitative analysis of the loss of mitochondrial membrane potential (TMRE) and Annexin V positivity in 22Rv1 and PC3 cells treated for the indicated time points with $20 \mu \mathrm{M}$ sorafenib, (means \pm S.D., $n \geq 3$ ); (c) Immunoflourescent staining and quantification of mitochondrial membrane potential (appearing in red, mitotracker) and cytochrome $c$ (appearing in green, FITC) in 22Rv1 and PC3 treated with $20 \mu \mathrm{M}$ sorafenib for $24 \mathrm{~h}$; (d) Immunoblot analysis of the indicated proteins involved in the execution of apoptotic cell death of $22 \mathrm{Rv} 1$ and PC3 cells treated with $20 \mu \mathrm{M}$ sorafenib for $48 \mathrm{~h}$; (e) Quantitative analysis of Annexin V/PI positivity in 22Rv1 and PC3 pre-treated with either $10 \mu \mathrm{M}$ zVAD.fmk or $50 \mu \mathrm{M}$ Necrostatin 1 followed by $20 \mu \mathrm{M}$ sorafenib for $24 \mathrm{~h}$ (means \pm s.d., $n \geq 3$ )

Apart from the transcription factors that are regulated by active ERK 1/2 (e.g., c-fos, ets), a number of apoptosis-related proteins, such as Bad, are also directly affected. ${ }^{7}$ Bad phosphorylation was partially inhibited by sorafenib, correlating with the inhibition of ERK phosphorylation (Figure 2d). The importance of ERK1/2 phosphorylation in sorafenib-induced 
a

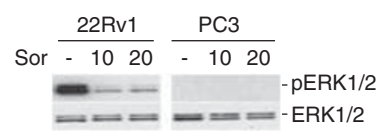

C

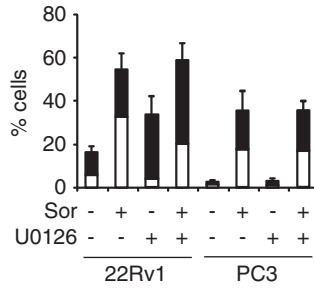

e

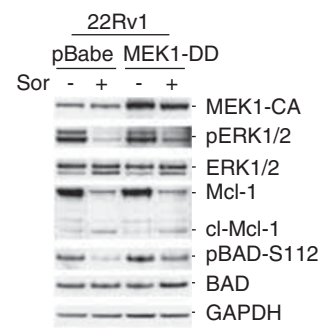

g

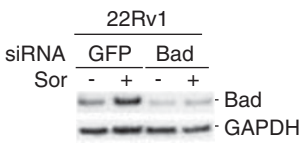

b

\begin{tabular}{|c|c|c|c|c|c|c|}
\hline & \multicolumn{5}{|c|}{ Sor } & \\
\hline \multicolumn{3}{|c|}{ 22Rv1 } & \multicolumn{3}{|c|}{ PC3 } & \\
\hline- & 8 & 1624 & & 8 & $16 \quad 24$ & (h) \\
\hline - & - & & & & & - pERK $1 / 2$ \\
\hline$=$ & $=$ & $=$ & & & $=\equiv=$ & - ERK1/2 \\
\hline
\end{tabular}

d

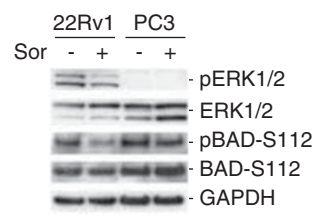

f

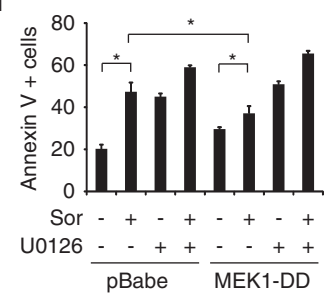

h

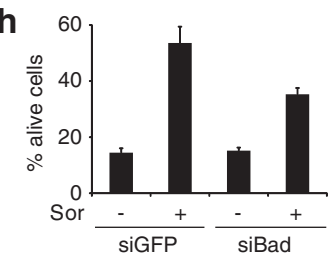

Figure 2 Inhibition of ERK phosphorylation is necessary, but not sufficient for Sorafenib-induced apoptosis in 22Rv1 cells. (a) Immunoblot analysis of phosphorylated and total ERK1/2 in 22Rv1 and PC3 cells treated with the indicated doses of sorafenib for $24 \mathrm{~h}$; (b) Immunoblot analysis of phosphorylated and total ERK1/2 in 22Rv1 and PC3 cells treated with $20 \mu \mathrm{M}$ sorafenib for the indicated time points; (c) Quantitative analysis of Annexin V/PI positive, 22Rv1 and PC3 cells pre-treated with U0126 followed by $20 \mu \mathrm{M}$ sorafenib for $24 \mathrm{~h}$ (means \pm S.D., $n \geq 3$ ); (d) Immunoblot analysis of the indicated proteins in 22Rv1 and PC 3 cells treated with $20 \mu \mathrm{M}$ sorafenib for $24 \mathrm{~h}$; (e) Immunoblot analysis of the indicated proteins in 22Rv1 transiently transfected with either an empty vector or constitutively active MEK1 (MEK1-DD) and treated with $20 \mu \mathrm{M}$ sorafenib for $24 \mathrm{~h}$; (f) Quantitative analysis of Annexin V/PI positive, 22Rv1 cells transfected with either an empty vector or with constitutively active MEK1 (MEK1-DD) and treated with $20 \mu \mathrm{M}$ sorafenib for $24 \mathrm{~h}$ (means \pm S.D., $n \geq 3,{ }^{*} P<0.05$ ); (g) Immunoblot analysis of Bad in 22Rv1 cells transiently transfected with either GFP siRNA or with Bad siRNA and treated with $20 \mu \mathrm{M}$ sorafenib for $24 \mathrm{~h}$; (h) Quantitative analysis of Annexin V/PI positive of 22Rv1 cells transiently transfected with either GFP siRNA or with Bad siRNA and treated with $20 \mu \mathrm{M}$ sorafenib for $48 \mathrm{~h}$ (means \pm S.D., $n \geq 3$ )

cell death was further examined by transfecting 22Rv1 cells with a constitutively active MEK1 construct, MEK1-DD (Figure $2 e$ and f). Notably, MEK1-DD overexpression attenuated the sorafenib-induced inhibition of ERK1/2 phosphorylation and the dephosphorylation of the downstream target Bad, yet did not alter sorafenib-induced $\mathrm{Mcl}-1$ downregulation and cleavage (Figure 2e). Importantly, MEK1-DD overexpression significantly inhibited sorafenib-induced cell death in 22Rv1 cells, an effect that could be reversed by the co-administration of the MEK1 inhibitor U0126 (Figure 2f). The role of Bad in sorafenib-induced cell death was further substantiated by depleting 22Rv1 cells from Bad using suitable siRNA. We found that knocking down of Bad attenuates the cytotoxic

efficacy of sorafenib (Figure $2 \mathrm{~g}$ and $\mathrm{h}$ ). Overall these data suggest that 22Rv1 cells require an active Raf/MEK/ERK pathway to survive and that interrupting this pathway by sorafenib leads to the activation of Bad and consequent cell killing.

Inhibition of the Src-AKT pathway is required for sorafenib-induced cell death in PC3 cells. Loss of PTEN expression is frequently observed in prostate cancer. In PC3 cells, PTEN is not expressed leading to an uninhibited and constitutively active PI3K/AKT pathway secondary to upstream tyrosine kinases such as Src. ${ }^{4}$ Src and AKT were constitutively phosphorylated in PC3 cells, and this activation was largely blocked by sorafenib (Figure 3a). One downstream target of AKT is the transcription factor FOXO, which is known to regulate the expression of the $\mathrm{BH} 3-$ only protein Bim. Treatment of PC3 cells with sorafenib induced the expression of the Bim-EL isoform. As expected, pharmacological inhibition of the PI3K/AKT pathway by Ly294002 did not induce any significant changes in 22Rv1 cells. However, in PC3 cells, Ly294002 had minor cytotoxic effects, when added alone, and further potentiated sorafenibinduced cell death (Figure 3b). Transient transfection of PC3 cells with a constitutively active AKT construct led to protection from sorafenib-induced cell death (Figure $3 c$ and d). To substantiate the importance of the induction of Bim as a result of the inhibition of AKT phosphorylation, Bim was transiently knocked down and the effect of this transfection on sorafenib-induced cell death was examined by immunoblotting and flow cytometry (Figure $3 e$ and f). Knockdown of Bim partially protected PC3 cells from sorafenib-induced killing, supporting the implication of the PI3K/AKT/Bim axis in sorafenib-mediated PC3 cell killing. Furthermore, knocking down of Bak in PC3 cells partially protects from sorafenib-induced cell death (Supplementary Figure $2 a$ and $b$ ).

Sorafenib induces cytoprotective autophagy in 22Rv1 and PC3 cells. Induction of autophagy in response to TKIs including sorafenib ${ }^{14}$ has been observed by us and others, and autophagy may contribute or reduce cell death responses, depending on the metabolic state of the cells. $^{20,21}$ Treatment of 22Rv1 and PC3 with sorafenibinduced LC3-GFP $^{+}$cytoplasmic foci characteristic of autophagic vacuoles (Figure $4 \mathrm{a}$ and b). Apart from LC3 accumulation in autophagosomes, other hallmarks of autophagy, such as LC3 lipidation and p62 degradation, were observed in 22Rv1 and PC3 treated with sorafenib (Figure 4c). Chemical inhibition of early and late autophagy with 3-methyladenine or chloroquine did not reduce, but rather potentiated sorafenib-induced cell death in PC3 cells to levels similar induced in 22Rv1, suggesting that PC3 cells activate a cytoprotective autophagic response (Figure 4d). Transient knockdown of Atg5 in 22Rv1 and PC3 led to potentiation of sorafenib-induced cell death, further confirming the cytoprotective role of autophagy in this context (Figure 4e and f). In summary, these data suggest that autophagy is induced in response to sorafenib to protect 22Rv1 and PC3 cells and that suppressing autophagy can improve the efficacy of sorafenib. 

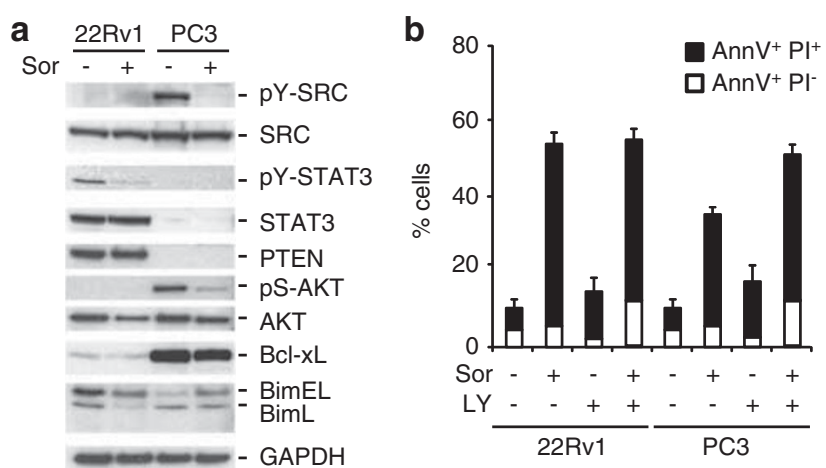

C
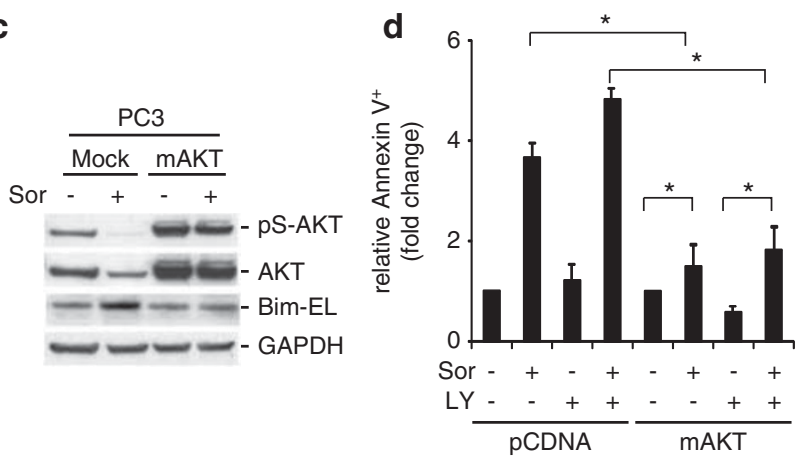

e
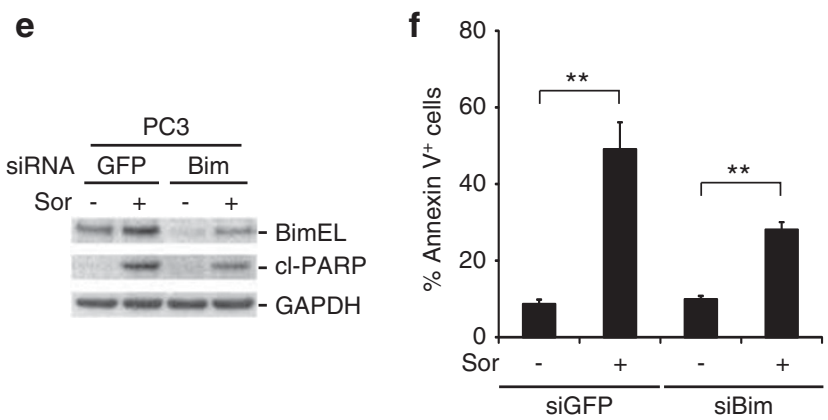

Figure 3 Inhibition of Src-AKT pathway is required for sorafenib-induced cell death in PC3 cells. (a) Immunoblot analysis of the indicated proteins in 22Rv1 and PC3 cells treated with $20 \mu \mathrm{M}$ sorafenib for $24 \mathrm{~h}$; (b) Quantitative analysis of Annexin V/PI positive, 22Rv1 and PC3 cells pre-treated with LY294002 followed by $20 \mu \mathrm{M}$ sorafenib for $24 \mathrm{~h}$ (means \pm S.D., $n \geq 3$ ); (c) Immunoblot analysis of phosphorylated and total AKT in PC3 cells transiently transfected with either an empty vector or with constitutively active AKT and treated with $20 \mu \mathrm{M}$ sorafenib for $24 \mathrm{~h}$; (d) Quantitative analysis of Annexin V/PI positive of PC3 cells transiently transfected with either an empty vector or with constitutively active AKT and treated with $20 \mu \mathrm{M}$ sorafenib for $24 \mathrm{~h}$ (means \pm S.D., $n \geq 3,{ }^{*} P<0.05$ ); (e) Immunoblot analysis of Bim and cleaved PARP (cl-PARP) in PC3 cells transiently transfected with either GFP siRNA or with Bim siRNA and treated with $20 \mu \mathrm{M}$ sorafenib for $24 \mathrm{~h}$; (f) Quantitative analysis of Annexin V/PI positive of PC3 cells transiently transfected with either GFP siRNA or with Bim siRNA and treated with $20 \mu \mathrm{M}$ sorafenib for $24 \mathrm{~h}$ (means \pm S.D., $n \geq 3,{ }^{\star \star} P<0.01$ )

Mcl-1 inactivation is required for sorafenib-induced apoptosis. The dependence of sorafenib-induced cell death on the downregulation of $\mathrm{Mcl}-1$ protein levels has been well described for other malignancies. ${ }^{22}$ Accordingly, sorafenib-induced $\mathrm{Mcl}-1$ downregulation in a time and dosedependent manner (Figure $5 \mathrm{a}$ and b). In 22Rv1, Mcl-1 is cleaved to the $27 \mathrm{kDa}$ fragment, whereas in PC3, Mcl-1 total protein levels are downregulated. Ectopic overexpression of wild-type $\mathrm{Mcl}-1$ led to inhibition of sorafenib-induced cell death in both 22Rv1 and PC3 cells (Figure 5c and d).
As sorafenib targets one of the three main anti-apoptotic $\mathrm{Bcl}-2$ family members, $\mathrm{Mcl}-1$, we hypothesized that co-inactivation of $\mathrm{Bcl}-2$ and $\mathrm{Bcl}-\mathrm{xL}$ by the co-administration of the $\mathrm{Bcl}-2 / \mathrm{Bcl}-\mathrm{xL}$ antagonist, $\mathrm{ABT} 737$ should potentiate the efficacy of sorafenib-induced cell death. Indeed, co-treatment of 22Rv1 and of PC3 cells with sorafenib and ABT737 significantly improved the efficacy of in vitro chemotherapy, as compared with treatment with sorafenib alone (Figure $5 \mathrm{e}$ and f). Importantly, such effects were not observed for the combination of sorafenib with ABT737 in normal prostate cells (Supplementary Figure 3 ). Collectively, these data indicate that the anti-apoptotic Bcl-2 family members $\mathrm{Mcl}-1$, $\mathrm{Bcl}-2$ and $\mathrm{Bcl}-\mathrm{xL}$ protect prostate cancer cells from sorafenibinduced cell death and simultaneous targeting of several antiapoptotic proteins can lower the apoptotic threshold of 22Rv1 and PC3 prostate cancer cells.

CAFs protect from sorafenib-induced cell death. It has recently been suggested that the tumor microenvironment, apart from promoting tumor growth, might also confer resistance to therapy. ${ }^{23}$ Here, we examined the role of CAFs in modulating the response of 22Rv1 and PC3 to sorafenib alone or in combination with ABT737. The fibroblast nature of the tissue-derived cell cultures was verified by their fibroblast-characteristic morphology and the expression of fibroblast markers such as PDGFR- $\beta, \alpha$ SMA but not for example, E-CADHERIN (Figure $6 a$ and b). Administration of sorafenib for $48 \mathrm{~h}$-induced cell death in 22Rv1 and PC3 monocultures, and this cytotoxic effect abrogated in co-cultures with CAFs (Figure $6 c$ and $e$ ). However, treatment with ABT737 or, more convincingly, with sorafenib plus ABT737 re-established the sensitivity of 22Rv1 and PC3 cells to cell killing in spite of the presence of CAFs (Figure $6 c$ and $e$ ).

In an attempt to delineate the mechanisms mediating the cytoprotective effect of CAFs on 22Rv1 and PC3, several key signaling cascades were examined. The majority of the signaling cascades examined in this paper were inhibited by sorafenib even in the presence of CAFs (Figure 6d). However, a major difference was found with respect to ERK phosphorylation, which could not be inhibited any more by sorafenib in the presence of CAFs. Furthermore, there was an increase in LC3 lipidation in sorafenib-treated 22Rv1 cells grown in the presence of CAFs indicative of increased autophagy. In PC3 cells, AKT phosphorylation and $\mathrm{Bcl}-\mathrm{xL}$ protein levels were sustained in the presence of CAFs, thus providing survival signals for $\mathrm{PC} 3$ to resist sorafenib-induced cell death (Figure 6f). Thus, tumor fibroblasts can protect prostate cancer cells from sorafenib, at last in PC3 by the upregulation of Bcl- $X_{L}$ and co-administration of $A B T 737$ can revert this CAF-mediated resistance (Figure $6 \mathrm{c}$ and $\mathrm{e}$ ).

\section{Discussion}

In the present study we have delineated the signaling cascades targeted by sorafenib to induce cell death in two prostate cancer cells 22Rv1 and PC3. One striking difference between these two cell lines is that 22Rv1 activate the apoptotic pathway earlier and to a larger extent than in PC3 cells. In 22Rv1, cytochrome $c$ is released, caspases are 
a

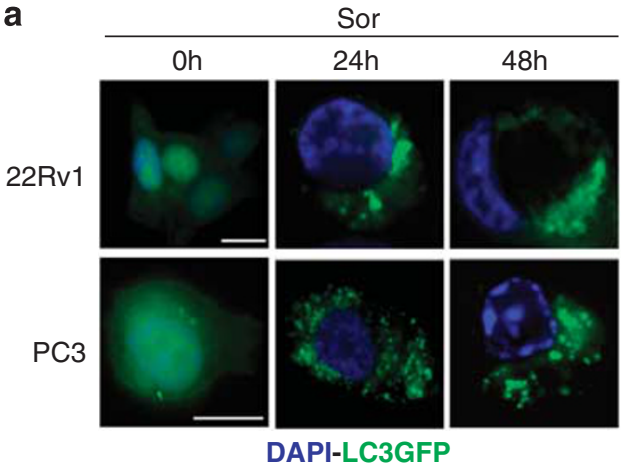

C

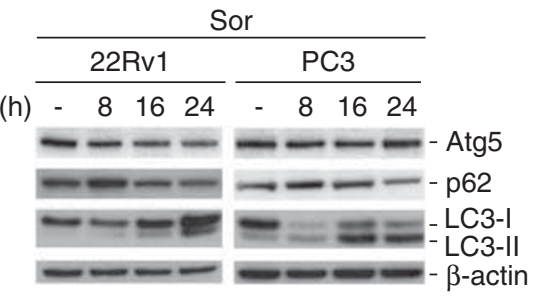

e

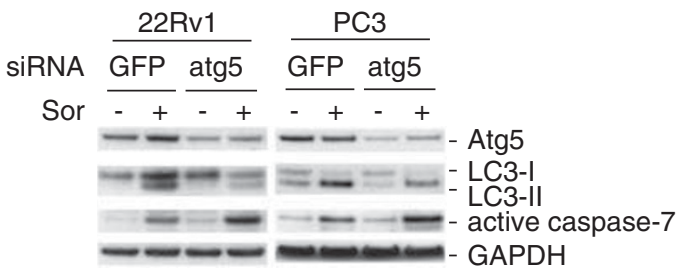

b

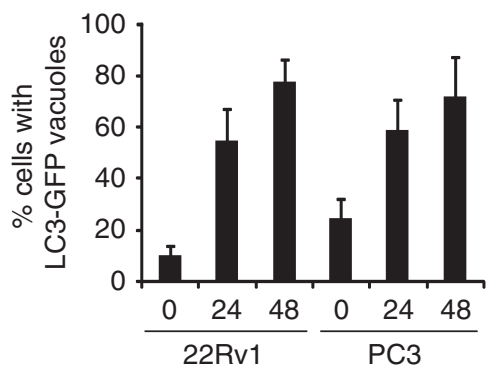

d

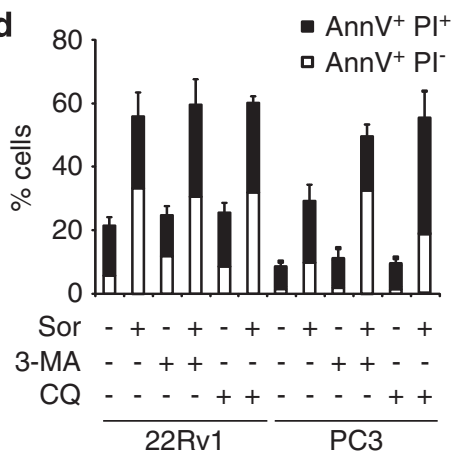

f

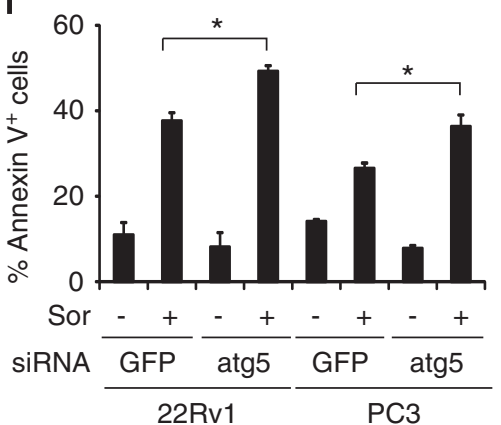

Figure 4 Sorafenib induces cytoprotective autophagy in 22Rv1 and PC3 cells. (a) Immunoflourescent staining of 22Rv1 and PC3 stably transfected with LC3-GFP and treated with $20 \mu \mathrm{M}$ sorafenib for $24 \mathrm{~h}$; (b) The percentage of cells with LC3-GFP foci was quantified by counting cells untreated or treated with $20 \mu \mathrm{M}$ sorafenib for the indicated time points (means \pm S.D., $n$ : 3 fields of 100 cells). (c) Immunoblot analysis of the indicated proteins in 22Rv1 and PC 3 cells treated with $20 \mu \mathrm{M}$ sorafenib for $24 \mathrm{~h}$. (d) Quantitative analysis of Annexin V/PI positive, 22Rv1 and PC3 cells pre-treated with either $5 \mathrm{mM}$ 3-methyladenine (3-MA) or $10 \mu \mathrm{M}$ chloroquine (CQ) followed by $20 \mu \mathrm{M}$ sorafenib for $24 \mathrm{~h}$ (means $\pm \mathrm{SD}, n \geq 3$ ); (e) Immunoblot analysis of the indicated proteins in $22 R v 1$ and PC3 cells transiently transfected with either GFP siRNA or with atg5 siRNA and treated with $20 \mu \mathrm{M}$ sorafenib for $24 \mathrm{~h}$. (f) Quantitative analysis of Annexin V/PI positive of 2 Rv1 and PC3 cells transiently transfected with either GFP siRNA or with atg5 siRNA and treated with $20 \mu \mathrm{M}$ sorafenib for $24 \mathrm{~h}$ (means \pm S.D., $n \geq 3,{ }^{\star} P<0.05$ )

activated and PARP is cleaved, within $24 \mathrm{~h}$. In contrast, PC3 cells have to be treated for up to $48 \mathrm{~h}$ before a substantial amount of apoptotic cell death can be detected. The kinetic difference between these two cell lines cannot be explained by looking into the molecular components of the core apoptotic signaling cascade. Rather, the signaling cascades targeted by sorafenib seem to define the time and the extent of the cell death induced.

One of the best-characterized targets of sorafenib is the Raf/ MEK/ERK pathway. ${ }^{24}$ This pathway is constitutively active in 22Rv1, but not in PC3 cells. Sorafenib potently inhibits the Raf/ MEK/ERK axis. The importance of the constitutively active ERK for the survival of 22Rv1 was demonstrated by chemical inhibitors and molecular activators, indicating that targeting of this pathway in $22 R v 1$ cells is critical for their survival. One of the downstream targets of ERK $1 / 2$ is Bad, the phosphorylation of which promotes its interaction with 14-3-3 proteins thereby preventing it from triggering apoptosis. ${ }^{25}$ Sorafenib treatment led to a decrease in the serine 112 phosphorylation of Bad, an event that was alleviated by the overexpression of the constitutively active MEK1-DD construct. Nevertheless, as the protection by MEK1-DD was not complete, additional lethal pathways must be activated in a parallel fashion by $22 R v 1$ cells responding to sorafenib.

With regard to the lack of ERK phosphorylation in PC3 cells, it has been previously reported that metastatic cell lines express low levels of the proteins involved in the Raf/MEK/ ERK axis. ${ }^{26}$ However, we did not observe this in PC3 cells as they expressed high levels of ERK1/2, but there were not phosphorylated. An alternative possibility that may account 
a

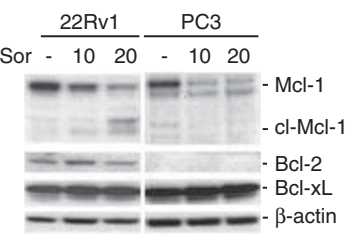

C

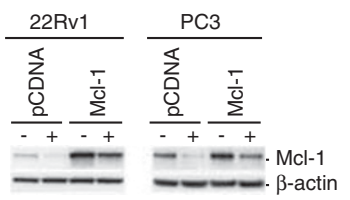

b

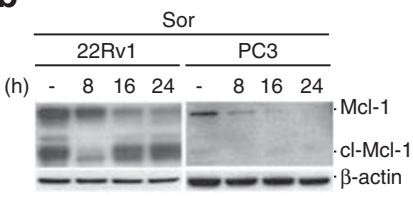

d

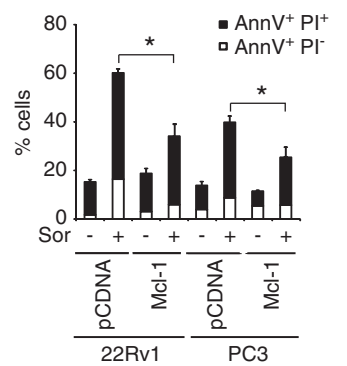

e

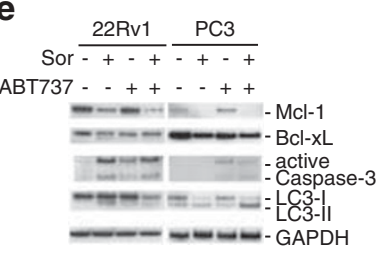

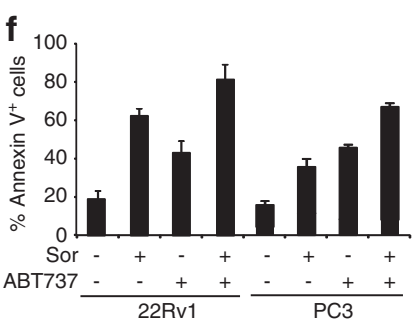

Figure $5 \mathrm{Mcl}-1$ downregulation is required for sorafenib-induced apoptosis. (a) Immunoblot analysis of Mcl-1, Bcl-xL and Bcl-2 in 22Rv1 and PC3 cells treated with the indicated doses of sorafenib for $24 \mathrm{~h}$; (b) Immunoblot analysis of Mcl-1 in 22Rv1 and PC3 cells treated with $20 \mu \mathrm{M}$ sorafenib for the indicated time points; (c) Immunoblot analysis of Mcl-1 in 22Rv1 and PC3 cells transiently transfected with either an empty vector or wild-type $\mathrm{Mcl}-1$ followed by treatment with $20 \mu \mathrm{M}$ sorafenib for $48 \mathrm{~h}$; (d) Quantitative analysis of Annexin V/PI positive of 22Rv1 and PC3 cells transiently transfected with either an empty vector or wild-type Mcl-1 followed by treatment with $20 \mu \mathrm{M}$ sorafenib for $48 \mathrm{~h}$ (means \pm S.D., $n \geq 3,{ }^{*} P<0.05$ ); (e) Immunoblot analysis of the indicated proteins in 22Rv1 cells treated with either $20 \mu \mathrm{M}$ sorafenib alone, with $10 \mu \mathrm{M} \mathrm{ABT737}$ alone or with a combination of sorafenib and ABT737 for $48 \mathrm{~h}$; (f) Quantitative analysis of Annexin V/PI positive, 22Rv1 and PC3 cells treated with either $20 \mu \mathrm{M}$ sorafenib alone, with $10 \mu \mathrm{M}$ ABT737 alone or with a combination of sorafenib and ABT737 for $48 \mathrm{~h}$ (means \pm S.D., $n \geq 3$ )

for the lack of ERK phosphorylation in PC3 cells is the reported inhibitory phosphorylation of Raf1 by AKT leading to the inactivation of Raf/MEK/ERK pathway. ${ }^{27}$ These two possibilities may account for the inactive state of ERK1/2 in PC3 cells and might also explain the attenuated levels of cell death induced by sorafenib in these cells.

Immunoblot analyses of the kinases activated in PC3 cells revealed several important observations. Apart from the welldescribed loss of PTEN expression and the constitutively active AKT, PC3 cells exhibited highly activated Src, a NRTK closely associated with CRPC. Treatment of PC3 cells with sorafenib-inhibited Src and AKT phosphorylation, correlating with an increase in Bim expression. The mechanism by which sorafenib inhibits Src and AKT is elusive. Src activation can be stimulated by multiple tyrosine kinases such as EGFR, VEGFR, PDGFR and FGFR. ${ }^{28}$ Thus, it is likely that targeted inhibition VEGFR and PDGFR may be responsible for the downstream inactivation of Src. The inhibition of AKT phosphorylation may be wither owing to the inhibition of the RTK-Src signaling cascades or via the inhibition of the RTKPI3K/AKT signaling cascades by sorafenib.
The role of autophagy in modulating the efficacy of cancer therapy is a conundrum. ${ }^{20}$ In some cases, inhibition of autophagy potentiates the efficacy of cancer therapeutics, and in other cases induction of autophagy promotes cell death. $^{20}$ In accordance with several reports on autophagy induction by TKIs we found that sorafenib potently stimulates autophagy and that autophagy inhibition exacerbated the apoptotic response of both 22Rv1 and PC3 cells to sorafenib.

One parameter that correlates well with prostate cancer progression towards CRPC is the expression of the antiapoptotic Bcl-2 family members. ${ }^{29,30}$ It has been well documented that one of the mechanisms by which sorafenib promotes its anti-tumoral effects is via the downregulation of Mcl-1. ${ }^{22}$ Sorafenib-induced Mcl-1 downregulation is mediated by translational inhibition and this seems to be the case in PC3, as mRNA levels did not change upon treatment (data not shown). In 22Rv1, Mcl-1 is inactivated via a well-described alternative mechanism, via caspase-dependent cleavage. In fact, another TKI induces apoptosis in hypereosinophilic cells via a caspase-3 dependent cleavage of Mcl-1. ${ }^{31}$ Our data confirm the importance of $\mathrm{Mcl}-1$ downregulation in both cell lines and found that it is pivotal to the execution of cell death induced by sorafenib. One of the consequences of $\mathrm{Mcl}-1$ inactivation is the ability to sequester and inhibit Bim-induced cell death. ${ }^{32}$ Apparently, in PC3 cells, shifting of the $\mathrm{Bcl}-2$ rheostat towards cell death occurs by inactivating one of the anti-apoptotic Bcl 2 family members, $\mathrm{Mcl}-1$ and by promoting the expression of the $\mathrm{BH} 3-o n l y$ protein $\mathrm{Bim}$. In 22Rv1, it is not Bim, which is even downregulated in response to sorafenib, but rather it is the dephosphorylation of Bad along with the inactivation of $\mathrm{Mcl}-1$ that tilts the balance towards cell death.

Despite the profound effects of sorafenib on oncogenic signaling cascades activated in PC3, cell death did not occur before $48 \mathrm{~h}$ and did not affect more than $30-40 \%$ of the cells. The cause of this resistance seems to be the remaining antiapoptotic $\mathrm{Bcl}-2$ family members $\mathrm{Bcl}-2$ and $\mathrm{Bcl}-\mathrm{xL}$ as treatment with ABT737 alone induces cell death in PC3 cells and the combination of sorafenib with ABT737 augmented this cytotoxic effect to levels similar as those detected in $22 \mathrm{Rv} 1$.

The tumor stroma and in particular, CAFs can modulate tumor growth and determine the response to therapy. In prostate cancer, the tumor stroma activates RTKs in the prostate cancer cells via the secretion of cytokines (e.g., PDGF, VEGF), hence stimulating the oncogenic signaling cascades Ras/Raf/MEK/ERK and PI3K/AKT. ${ }^{18}$ Here, we found that CAFs protected both 22Rv1 and PC3 cells from sorafenib-induced cell death. ERK phosphorylation was inhibited in 22Rv1 cells cultured in the presence of CAFs. Even though the source of this inhibition is elusive, it is tempting to speculate that as one of the main targets of sorafenib in 22Rv1, ERK, is dephosphorylated upon coculture with CAFs, 22Rv1 cells become resistant to this TKI. Furthermore, co-culturing of the CAFs with 22Rv1 leads to the downregulation of total Bad protein levels as well as the induction of $\mathrm{Bcl}-\mathrm{xL}$ protein, which in turn might render 22Rv1 cells more resistant to sorafenib. Evidence for this possibility comes from the ABT737-mediated sensitization of 22Rv1 cells to sorafenib. In addition, the observed increase in autophagy may also protect the 22Rv1 cells from cytotoxic effects of sorafenib. The highly metastatic PC3 cancer cells 
a
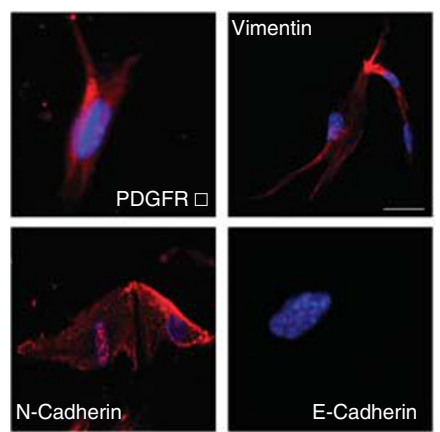

C

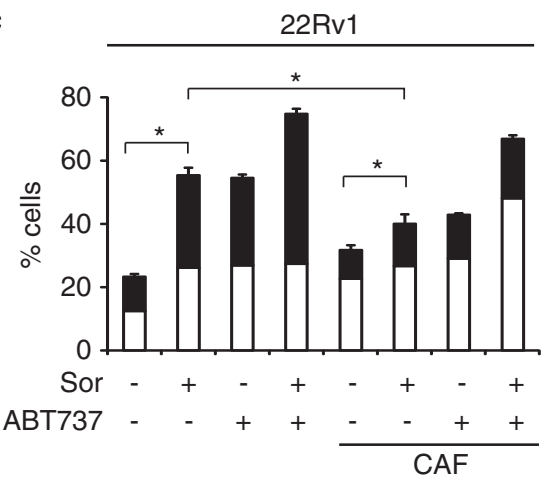

- $\mathrm{AnnV}^{+} \mathrm{PI}^{+} \quad \mathrm{AnnV} \mathrm{P}^{+} \mathrm{I}^{-}$

e

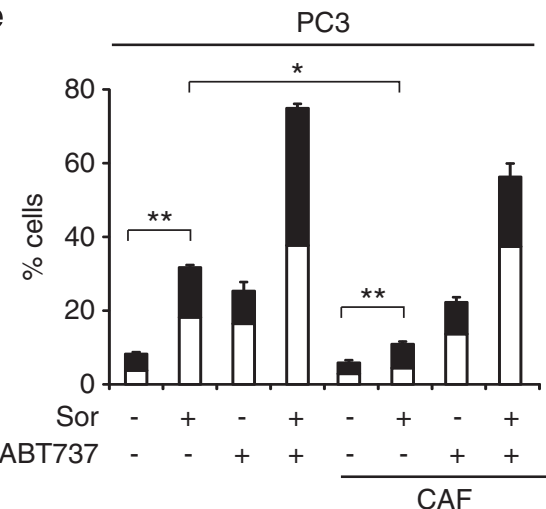

b

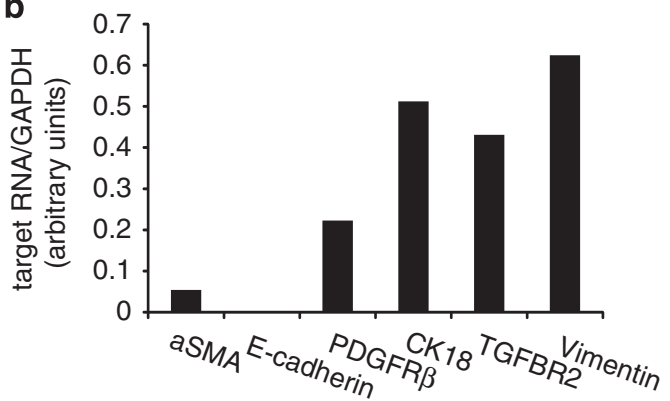

d

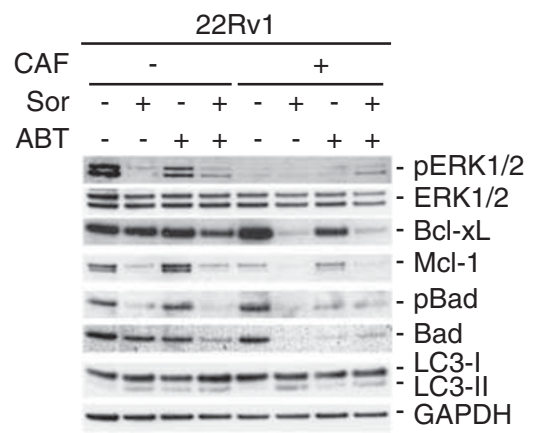

f

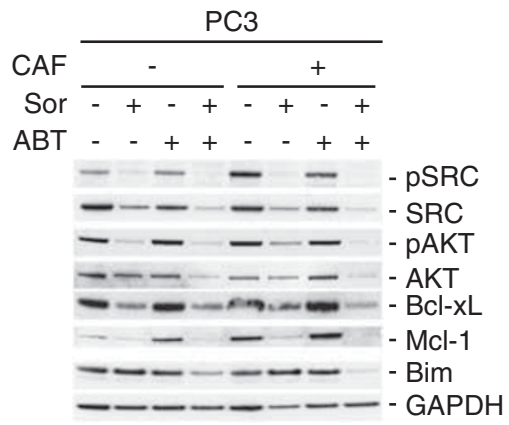

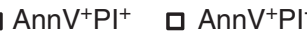

Figure 6 CAFs protect prostate cancer cells from sorafenib-induced cell death. (a) Immunoflourescent staining of E-Cadherin, N-Cadherin, PDGFR $\beta$ and Vimentin in CAFs; (b) Quantitative RT-PCR analysis of the expression of the indicated genes in primary CAFs; (c) Quantitative analysis of Annexin V positive of 22Rv1 cells treated with $20 \mu \mathrm{M}$ sorafenib for $48 \mathrm{~h}$ with or without $10 \mu \mathrm{M} \mathrm{ABT737,} \mathrm{either} \mathrm{in} \mathrm{monoculture} \mathrm{or} \mathrm{in} \mathrm{co-culture} \mathrm{with} \mathrm{CAFs} \mathrm{(means} \pm$ S.D., $n \geq 3,{ }^{*} P<0.05$ ); (d) Immunoblot analysis of the indicated proteins in 22Rv1 cells treated with the indicated doses of sorafenib for $24 \mathrm{~h}$ in the presence or absence of CAFs; (e) Quantitative analysis of Annexin V positive of PC3 cells treated with $20 \mu \mathrm{M}$ sorafenib for $48 \mathrm{~h}$ with or without $10 \mu \mathrm{M} \mathrm{ABT737}$, either in monoculture or in co-culture with CAFs (means \pm S.D., $n \geq 3,{ }^{\star} P<0.05,{ }^{* \star} P<0.01$ ); (f) Immunoblot analysis of the indicated proteins in PC3 cells treated with the indicated doses of sorafenib for $24 \mathrm{~h}$ in the presence or absence of CAFs

were completely protected from sorafenib-induced cell death when cultured with CAFs. In this setting, the paracrine signaling cascades lead to a sustained phosphorylation/ activation of AKT, thereby providing multiple mechanisms of survival in PC3 cells. Interestingly Bim induction was not affected by the sustained AKT phosphorylation suggesting that its expression is regulated by alternative mechanisms. Importantly, Bcl-xL protein levels were higher in PC3 cells cultured with CAFs than without CAFs, indicating that this could be one of the mechanisms by which PC3 cells resist sorafenib.
Importantly, the observed resistance to sorafenib in 22Rv1 and PC3 cells co-cultured with primary CAFs could be reverted by the administration of ABT737. This result indicates that anti-apoptotic Bcl-2 family members are largely responsible for the lack of efficacy of sorafenib. Addition of CAFs increased the expression of $\mathrm{Bcl}-\mathrm{xL}$ in $\mathrm{PC} 3$ cells, indicating that this CAF-induced $\mathrm{Bcl}-\mathrm{xL}$ must be the target of ABT737. These data strongly suggest that the combination of sorafenib with ABT737 or other, more specific Bcl-xL inhibitors should be evaluated for the therapy of metastatic prostate cancer. 


\section{Materials and Methods}

Cell lines and culture conditions. 22Rv1 and PC-3 prostate cancer cell lines were all cultured in RPMI 1640 (Hyclone, Erembodegem, Belgium) enriched with $10 \%$ fetal bovine serum (Hyclone), glutamine (2 mM) penicillin and streptomycin $(50 \mu \mathrm{g} / \mathrm{ml})$ (GIBCO, Stockholm, Sweden). CRL-2221, immortalized normal prostate epithelium, were cultured in Keratinocyte-SFM Medium (GIBCO) supplemented with L-glutamine, epidermal growth factor and bovine pituitary extract. All cell lines were kept at $37^{\circ} \mathrm{C}$ in a humidified air incubator and $5 \% \mathrm{CO}_{2}$. All cell lines were obtained from American Type Culture Collection (Manassas, VA, USA) and were authenticated by LGC standards cell line authentication service.

Primary CAFs. Primary human prostate fibroblast cultures were established as previously described. ${ }^{34}$ In brief, fresh prostate tissue was harvested from cut surfaces of radical prostatectomy specimens. For morphological control, Giemsa stained cytological smears were used and parallel histological sections were reviewed. The tissue samples were diced in about $1 \mathrm{~mm}^{3}$ pieces that were put into 6-well tissue culture plates and fixed in the well under a cover slide. Then $1.5 \mathrm{ml} \mathrm{Bfs}$ medium (DMEM (Hyclone) supplemented with 5\% FBS (Hyclone), 5\% Nu Serum (BD Biosciences, Stockholm, Sweden), $5 \mathrm{mg} / \mathrm{ml}$ insulin, $0.5 \mu \mathrm{g} / \mathrm{ml}$ testosterone, $4 \mathrm{mM} \mathrm{L-glutamine}$ and $1 \mathrm{x}$ Penicillin/Streptomycin (Sigma, Stockholm, Sweden)) was added to each well and the tissue pieces were incubated at $37^{\circ} \mathrm{C}$ with $5 \% \mathrm{CO}$. Fibroblast-like cells started to migrate out from the tissue between 5 and 15 days and were passaged when confluent. Cultures at passages 8-11 were used in this study.

Co-culture experiments. 22Rv1 or PC3 were plated in 12-well plates $2 \mathrm{~h}$ before putting cell culture inserts (BD Falcon, Franklin Lakes, NJ, USA), which contain CAFs. The cells were incubated together overnight in $5 \% \mathrm{CO}_{2}$ incubator before treatment.

Preparation of sorafenib. Sorafenib was provided by Bayer HealthCare Pharmaceuticals, Inc. (Wayne, NJ, USA). Sorafenib was dissolved in DMSO and final dosing solutions were prepared on the day of use from a stock solution. In all the experiments, $20 \mu \mathrm{M}$ sorafenib was used unless stated otherwise.

Antibodies and reagents. The pancaspase inhibitor z-VAD-FMK (z-Val-Ala-Asp(OMe)-FMK) (MP Biomedicals, Illkirch, France) was used at $10 \mu \mathrm{M}$, 3-methyladenine (3-MA) (Sigma-Aldrich, Stockholm, Sweden) was used at $5 \mathrm{mM}$, Necrostatin1 (Sigma-Aldrich) was used at $50 \mu \mathrm{M}$, Chloroquine (Sigma-Aldrich Sweden AB, Stockholm, Sweden) at $10 \mu \mathrm{M}, \mathrm{ABT737}$ (active biochemical Co. Hong Kong, PR China) at $10 \mu \mathrm{M}$, Rapamycin at $1 \mu \mathrm{M}$, U0126 (Sigma-Aldrich) at $10 \mu \mathrm{M}, \mathrm{LY} 294002$ (Sigma-Aldrich) at10 $\mu \mathrm{M}$.

The primary antibodies used in this study pSrc (Y416), Src, MEK1, phosphoERK1/2 (Thr202/Tyr204), ERK1/2 PTEN, cleaved caspase-3, cleaved caspase-7, cleaved-PARP, phosphor-AKT (Ser473), AKT, pBAD (Ser112), BAD, ATG-5, Mcl-1, LC3 I/II, BCl-2, PDGFR $\beta$, phosphoY705 STAT3 and STAT3 were obtained from Cell Signaling Technology (Danvers, MA, USA), p62 from Abnova (Heidelberg, Germany), Bim from Stressgene (Plymouth Meeting, PA, USA), Bcl-xL from Transduction Laboratories (Franklin Lakes, NJ, USA), GAPDH and N-cadherin from Abcam (Cambridge, UK), $\beta$-actin from Sigma-Aldrich, Bak, Bax, E-cadherin, vimentin from BD Biosciences, AIF from Santa Cruz Biotechnology (Heidelberg, Germany).

siRNA sequences, plasmids and transfections. Transfection with plasmids and siRNA experiments where performed according to protocols provided by Invitrogen (Stockholm, Sweden). Lipofectamine 2000 (Invitrogen) was used for all transfections with Mcl-1, MEK-CA and myrAKT. Oligofectamine (Invitrogen) was used for transfections of siGFP (Silence, AM4626, Ambion, Stockholm, Sweden), siATG5 (siATG : 5'-GCA GAA CCA UAC UAU UUGGTT-3') and siBim (SignalSilence Bim siRNA I), siBak (5'-GCGAAGUCUUUG CCUUCUC-3'), siBad (5'-GAAGGGACUUCCUCGCCCG-3'). Mcl-1 wild-type plasmid was produced by cloning of Mcl-1 segment of Mcl-1PGEX plasmid (kindly provided by Dr Auberger) into pCDNA3.3, pBabe-Puro-MEK-DD, which expresses activated MEK1-DD (S218D/S222D) constitutively, and myristoylated AKT plasmids were acquired from AddGene Inc. (Cambridge, MA, USA).

Assessment of apoptosis and immunostainings for flow cytometry. Redistribution of plasma membrane phosphatidylserine is a marker of apoptosis and was assessed by Annexin fluorescein isothiocyanate (MACS, Miltenyi Biotech, Bergisch Gladbach, Germany). ${ }^{35}$ Briefly, $2 \times 10^{5}$ cells per sample were collected, washed in PBS, pelleted and re-suspended in incubation buffer (10 mM HEPES/NaOH, pH 7.4, $140 \mathrm{mM} \mathrm{NaCl}, 5 \mathrm{mM} \mathrm{CaCl}_{2}$ ) containing $1 \%$ Annexin V and PI. Samples were incubated for $10 \mathrm{~min}$ before analysis on a fluorescence-activated cell sorter Calibur flow cytometer (Becton Dickinson, Franklin Lakes, NJ, USA) using Cell Quest software (San Jose, CA, USA).

To detect sorafenib changes in mitochondrial membrane potential, cell were stained with tetramethylrhodamine ethyl ester perchlorate and measure by flow cytometry (TMRE; Invitrogen) as previously described. ${ }^{36}$ Briefly, $1 \mathrm{nM}$ TMRE was added to $10^{6} \mathrm{cells}$ and the cells were incubated for $30 \mathrm{~min}$. After washing the cells in PBS and TMRE, they were incubated for $10 \mathrm{~min}$ in the dark in $100 \mu \mathrm{l}$ of incubation buffer (10 mM HEPES/NaOH, pH 7.4, $140 \mathrm{mM} \mathrm{NaCl,} 5 \mathrm{mMCaC12}, 25 \mathrm{nM}$ TMRE) containing $1 \%$ Annexin V FLUOS.

Immunocytochemistry. The effect of sorafenib on prostate cancer cell lines was analysed by staining of mitochondria with MitoTracker and co staining with cytochrome $c$ antibody as previously described. ${ }^{37}$ Briefly, for mitochondrial stainings, cells were incubated for $30 \mathrm{~min}$ in normal growth medium containing $5 \mu \mathrm{M}$ MitoTracker (Mol. Probes, Inc., Stockholm, Sweden). Cells were then cytospun on glass slides, fixed in 4\% PFA for 20 min, permeabilized using digitonin diluted in PBS for 10 min and stained with anti- cytochrome $c$ antibodies for $1 \mathrm{~h}$ at RT, followed by rabbit-anti-mouse FITC-conjugated antibodies (DAKO, Stockholm, Sweden). For the immunostainings of the primary CAFs, $\sim 2500$ fibroblasts were seeded on a gelatin coated, sterile, eight chamber glass slide (Lab-Tek II, Nalge Nunc Int, Roskilde, Denmark) and allowed to attach for $24 \mathrm{~h}$ in incubator. Cells were fixed with $4 \%$ PFA in PBS for 20 min at $4{ }^{\circ} \mathrm{C}$. After incubation with PBS containing $10 \%$ goat serum for $1 \mathrm{~h}$ at room temperature, the cells were incubated with the indicated antibodies for $90 \mathrm{~min}$ at room temperature. Subsequently, the sections were incubated with a texas red - conjugated anti-mouse (Vector Laboratories, Burlingame, CA, USA) both diluted $1: 100$ in PBS with $10 \%$ goat serum for $30 \mathrm{~min}$ at $37^{\circ} \mathrm{C}$. The sections were mounted with Vectashield mounting media with DAPI (Vector Laboratories). The images were recorded on a DAS Leitz DM RB microscope with a Zeiss Axioplan-2 microscope with a Zeiss dual mode cooled CCD camera (Zeiss, Stockholm, Sweden) and Axiovision software 4.1 (Stockholm, Sweden).

Cell cycle analysis. We use NucleoCounter NC-3000 from chemometec (Allerød, Denmark) to analysis cell cycle according to the manufacturer's specifications. One million cells were harvested and washed by PBS then resuspended in $0.5 \mathrm{ml}$ Solution 10 supplemented with $10 \mu \mathrm{g} / \mathrm{ml}$ DAPI. Cells were incubated at $37^{\circ} \mathrm{C}$ for $5 \mathrm{~min}$ then $0.5 \mathrm{ml}$ Solution 11 was added and $30 \mu \mathrm{l}$ of suspended cells was loaded on two-chamber slide (NC-Slide A2) and cell cycle was analyzed by using provided software.

Immunoblot analyses. Cells were harvested and homogenized in RIPA lysis buffer ( $10 \mathrm{mM}$ Tris, pH 7.2, $150 \mathrm{mM} \mathrm{NaCl}, 1 \%$ deoxycholate, $1 \%$ Triton, $0.1 \%$ SDS, $5 \mathrm{mM}$ EDTA) containing complete protease inhibitor cocktail (Roche Diagnostics, Meylan, France). After $1 \mathrm{~h}$ on ice, samples were sonicated and protein quantification was carried out using a Bio-Rad protein assay (Bio-Rad, Sundbyberg, Sweden). Equal amounts of soluble proteins $(15-25 \mu \mathrm{g})$ were denaturated by boiling and resolved by sodium dodecyl sulfate-polyacrylamide gel electrophoresis (SDS-PAGE) and transferred to a nitrocellulose membrane. After blocking in $5 \%$ non-fat dry milk in PBS for $1 \mathrm{~h}$ and probing with a specific primary antibody and a horseradish peroxidase-conjugated secondary antibody, the protein bands were detected by chemiluminescence (Supersignal, Pierce, Rockford, IL, USA) and X-ray film exposure (Kodak, Rochester, NY, USA). Protein loading was normalized by using anti-GAPDH or anti-actin antibodies.

Assessment of autophagy. For the LC3-GFP experiments, 22Rv1 and PC3 cells were transfected by $4 \mu \mathrm{g}$ of pEGFP-LC3 plasmid (kind gift from Dr Tamotsu Yoshimori and Dr. Noboru Mizushima from National Institute of Genetics, Japan) (Kabeya, 2000 no. 4449) using lipofectamine 2000 (Invitrogen) based on manufacturer's recommendation. Twenty four hours after transfection the growth media was replaced by complete RPMI 1640 supplemented with $1 \mathrm{mg} / \mathrm{ml} \mathrm{G} 418$ (Sigma). The cells cultured for 3 weeks under G418 selection pressure, and then EGFP-LC3-positive cells were selected by MoFlo XDP Cell Sorter (Beckman Coulter, Bromma, Sweden). Following treatment, the cells were fixed with $4 \%$ PFA and mounted using Vectashield with DAPI. The images were recorded on a Zeiss 
Axioplan-2 microscope with a Zeiss dual mode cooled CCD camera (Zeiss) and Axiovision software 4.1.

Real-time PCR. Real-time RT PCR was used to measure mRNA expression (ABI-PRISM 7500 Fast Real-Time PCR system, Applied Biosystems Inc., Foster City, CA, USA). Oligonucleotide primers were designed using Primer Express version 1.0 (Applied Biosystems Inc.). The Real-Time RT-PCR reaction volume was $15 \mu \mathrm{l}$, containing $4 \mathrm{ng}$ sample, forward primer (final concentration $0.4 \mu \mathrm{M}$ ), reverse primer (final concentration $0.4 \mu \mathrm{M}$ ) and SYBR Green PCR Master Mix- (4309155E, Applied Biosystems Inc.). The relative distribution of the transcripts of interest was measured; a $C_{T}$ value was obtained by subtracting the GAPDH $C_{T}$ values from respective target $C_{T}$ values. The expression of each target was then evaluated by $2^{-D C T}$.

\section{Conflict of Interest}

The authors declare no conflict of interest.

Acknowledgements. We thank the following people for kindly providing constructs and cell lines that were used in this study: Dr. Patrik Auberger for the Mcl-1 plasmid (Université de Nice Sophia Antipolis, France); Dr. Noboru Mizushima (The Tokyo Metropolitan Institute of Medical Science, Japan) for the LC3-GFP plasmid. ${ }^{33} \mathrm{TP}$ and DG are supported by Cancerfonden, Cancerföreningen, Åke Wiberg stiftelse, Socialstyrelsens fonder, Vetenskapsrådet. PK is supported by Karolinska Institutet funds for doctoral students (KID). GK is supported by Ligue contre le Cancer (équipe labellisée).

1. Tannock IF, de Wit R, Berry WR, Horti J, Pluzanska A, Chi KN et al. Docetaxel plus prednisone or mitoxantrone plus prednisone for advanced prostate cancer. N Engl J Med 2004; 351: 1502-1512.

2. Robinson D, He F, Pretlow T, Kung HJ. A tyrosine kinase profile of prostate carcinoma. Proc Natl Acad Sci USA 1996; 93: 5958-5962.

3. George DJ. Receptor tyrosine kinases as rational targets for prostate cancer treatment: platelet-derived growth factor receptor and imatinib mesylate. Urology 2002; 60 (3 Suppl 1): 115-121; discussion 122

4. Chang YM, Kung HJ, Evans CP. Nonreceptor tyrosine kinases in prostate cancer. Neoplasia 2007; 9: 90-100.

5. Gioeli D. Signal transduction in prostate cancer progression. Clin Sci (Lond) 2005; 108 : 293-308.

6. Papatsoris AG, Karamouzis MV, Papavassiliou AG. The power and promise of 'rewiring' the mitogen-activated protein kinase network in prostate cancer therapeutics. Mol Cancer Ther 2007; 6: 811-819.

7. Balmanno K, Cook SJ. Tumour cell survival signalling by the ERK1/2 pathway. Cell Death Differ 2008; 16: 368-377.

8. Samuels Y, Wang Z, Bardelli A, Silliman N, Ptak J, Szabo S et al. High frequency of mutations of the PIK3CA gene in human cancers. Science 2004; 304: 554.

9. Yoshimoto M, Cunha IW, Coudry RA, Fonseca FP, Torres CH, Soares FA et al. FISH analysis of 107 prostate cancers shows that PTEN genomic deletion is associated with poor clinical outcome. Br J Cancer 2007; 97: 678-685.

10. Yoshimoto M, Cutz JC, Nuin PA, Joshua AM, Bayani J, Evans AJ et al. Interphase FISH analysis of PTEN in histologic sections shows genomic deletions in $68 \%$ of primary prostate cancer and $23 \%$ of high-grade prostatic intra-epithelial neoplasias. Cancer Genet Cytogenet 2006; 169: 128-137.

11. Sun M, Wang G, Paciga JE, Feldman RI, Yuan ZQ, Ma XL et al. AKT1/PKBalpha kinase is frequently elevated in human cancers and its constitutive activation is required for oncogenic transformation in NIH3T3 cells. Am J Pathol 2001; 159: 431-437.

12. Urbich C, Knau A, Fichtlscherer S, Walter DH, Bruhl T, Potente M et al. FOXO-dependent expression of the proapoptotic protein Bim: pivotal role for apoptosis signaling in endothelial progenitor cells. FASEB J 2005; 19: 974-976.

13. Wilhelm SM, Carter C, Tang L, Wilkie D, McNabola A, Rong H et al. BAY $43-9006$ exhibits broad spectrum oral antitumor activity and targets the RAF/MEK/ERK pathway and receptor tyrosine kinases involved in tumor progression and angiogenesis. Cancer Res 2004; 64: 7099-7109.

14. Ullen A, Farnebo M, Thyrell L, Mahmoudi S, Kharaziha P, Lennartsson L et al. Sorafenib induces apoptosis and autophagy in prostate cancer cells in vitro. Int J Oncol 2010; 37: 15-20.

15. Chi KN, Ellard SL, Hotte SJ, Czaykowski P, Moore M, Ruether JD et al. A phase II study of sorafenib in patients with chemo-naive castration-resistant prostate cancer. Ann Oncol 2008; 19: 746-751.
16. Dahut WL, Scripture C, Posadas E, Jain L, Gulley JL, Arlen PM et al. A phase II clinical trial of sorafenib in androgen-independent prostate cancer. Clin Cancer Res 2008; 14 : 209-214.

17. Steinbild S, Mross K, Frost A, Morant R, Gillessen S, Dittrich C et al. A clinical phase II study with sorafenib in patients with progressive hormone-refractory prostate cancer: a study of the CESAR Central European Society for Anticancer Drug Research-EWIV. Br J Cancer 2007; 97: 1480-1485.

18. Karlou M, Tzelepi V, Efstathiou E. Therapeutic targeting of the prostate cancer microenvironment. Nat Rev Urol 2010; 7: 494-509.

19. Pietras K, Östman A. Hallmarks of cancer: Interactions with the tumor stroma. Exp Cell Res 2010; 316: 1324-1331.

20. Grander D, Panaretakis T. Autophagy: cancer therapy's friend or foe? Future Med Chem 2010; 2: 285-297.

21. Morselli E, Galluzzi L, Kepp O, Vicencio JM, Criollo A, Maiuri MC et al. Anti- and pro-tumor functions of autophagy. Biochem Biophys Acta 2009; 1793: 1524-1532.

22. Ding Q, Huo L, Yang JY, Xia W, Wei Y, Liao Y et al. Down-regulation of myeloid cell leukemia-1 through inhibiting Erk/Pin 1 pathway by sorafenib facilitates chemosensitization in breast cancer. Cancer Res 2008; 68: 6109-6117.

23. Farmer P, Bonnefoi H, Anderle P, Cameron D, Wirapati P, Becette V et al. A stroma-related gene signature predicts resistance to neoadjuvant chemotherapy in breast cancer. Nat Med 2009; 15: 68-74.

24. Liu L, Cao Y, Chen C, Zhang X, McNabola A, Wilkie D et al. Sorafenib blocks the RAF/MEK/ERK pathway, inhibits tumor angiogenesis, and induces tumor cell apoptosis in hepatocellular carcinoma model PLC/PRF/5. Cancer Res 2006; 66: $11851-11858$.

25. Datta SR, Katsov A, Hu L, Petros A, Fesik SW, Yaffe MB et al. 14-3-3 proteins and survival kinases cooperate to inactivate BAD by BH3 domain phosphorylation. Molecular Cell 2000; 6: $41-51$.

26. McCubrey JA, Steelman LS, Chappell WH, Abrams SL, Wong EW, Chang F et al. Roles of the Raf/MEK/ERK pathway in cell growth, malignant transformation and drug resistance. Biochem Biophys Acta 2007; 1773: 1263-1284.

27. Zimmermann S, Moelling K. Phosphorylation and regulation of Raf by Akt (protein kinase B). Science 1999; 286: 1741-1744.

28. Kim LC, Song L, Haura EB. Src kinases as therapeutic targets for cancer. Nat Rev Clin Oncol 2009; 6: 587-595.

29. Masuda M, Takano Y, Iki M, Asakura T, Hashiba T, Noguchi S et al. Prognostic significance of $\mathrm{Ki}-67, \mathrm{p53}$, and Bcl-2 expression in prostate cancer patients with lymph node metastases: a retrospective immunohistochemical analysis. Pathol Int 1998; 48: 41-46.

30. Bubendorf L, Sauter G, Moch H, Jordan P, Blochlinger A, Gasser TC et al. Prognostic significance of Bcl-2 in clinically localized prostate cancer. Am J Pathol 1996; 148: 1557-1565.

31. Pan J, Quintas-Cardama A, Manshouri T, Giles FJ, Lamb P, Tefferi A et al. The novel tyrosine kinase inhibitor EXEL-0862 induces apoptosis in human FIP1L1-PDGFR-alphaexpressing cells through caspase-3-mediated cleavage of Mcl-1. Leukemia 2007; 21: 1395-1404.

32. Herrant M, Jacquel A, Marchetti S, Belhacene N, Colosetti P, Luciano F et al. Cleavage of $\mathrm{Mcl}-1$ by caspases impaired its ability to counteract Bim-induced apoptosis. Oncogene 2004; 23: 7863-7873.

33. Kabeya Y, Mizushima N, Ueno T, Yamamoto A, Kirisako T, Noda T et al. LC3, a mammalian homologue of yeast Apg8p, is localized in autophagosome membranes after processing. EMBO J 2000; 19: 5720-5728.

34. Tuxhorn JA, Ayala GE, Smith MJ, Smith VC, Dang TD, Rowley DR. Reactive stroma in human prostate cancer: induction of myofibroblast phenotype and extracellular matrix remodeling. Clin Cancer Res 2002; 8: 2912-2923.

35. Castedo M, Ferri K, Roumier T, Metivier D, Zamzami N, Kroemer G. Quantitation of mitochondrial alterations associated with apoptosis. J Immunol Methods 2002; 265: 39-47.

36. Panaretakis T, Pokrovskaja K, Shoshan MC, Grander D. Activation of Bak, Bax, and BH3only proteins in the apoptotic response to doxorubicin. J Biol Chem 2002; 277: 44317-44326.

37. Panaretakis T, Pokrovskaja K, Shoshan MC, Grander D. Interferon-alpha-induced apoptosis in U266 cells is associated with activation of the proapoptotic Bcl-2 family members Bak and Bax. Oncogene 2003; 22: 4543-4556.

Cell Death and Disease is an open-access journal published by Nature Publishing Group. This work is licensed under the Creative Commons Attribution-Noncommercial-No Derivative Works 3.0 Unported License. To view a copy of this license, visit http://creativecommons.org/licenses/by-nc-nd/3.0/

\section{Supplementary Information accompanies the paper on Cell Death and Disease website (http://www.nature.com/cddis)}

